\title{
Evaluation of the extremely-low-frequency electromagnetic field (ELF-EMF) on growth of bacteria Escherichia coli
}

\author{
Yu Chen, Zhong Zhen Cai, Qian Feng, Peng Gao, Yongdong Yang, Xuemei Bai* and Bruce QTang \\ Institute of Life Science and Technology, ENN Group, Langfang, China
}

\begin{abstract}
The goal of this work was to evaluate the biological effect of the extremely-low-frequencies. We started by evaluating the effect of frequencies with the anti-bacterial functions listed in the Rife frequency database on the growth of Escherichia coli. Among the 11 sets of frequencies tested, we found that only one set comprising frequencies below $100 \mathrm{~Hz}$ showed a significant effect on the growth of $E$. coli, and it was an enhancement effect instead of an inhibition on growth. We further tested various sets of frequencies without anti-bacterial functions but comprising frequencies below $100 \mathrm{~Hz}$, and they all exhibited significant promoting effect on the growth of $E$. coli when exposed to the irradiation for $1 \mathrm{~h}$. We further evaluated the effect of the extremely low-frequency on the growth of $E$. coli by scanning from $0-100 \mathrm{~Hz}$. The results showed that the growth rate was noticeably enhanced for the group exposed to the irradiation at the range of $0-100 \mathrm{~Hz}$, with the range of 40-60 $\mathrm{Hz}$ being the most effective. In addition, the effect was time-dependent, demonstrated by a significant increase of growth rate observed after exposure of $1 \mathrm{~h}$ but a slight decrease for exposure of $16 \mathrm{~h}$. The results of this study provided robust data on the biological effect of ELF on the growth of E. coli, an important group of human microbiota, which has critical implication on the safety risk of these frequencies on human health.
\end{abstract}

\section{Introduction}

In the natural world, almost all living organisms are "immersed" in a variety of electromagnetic field (EMF), and interact with them. Living organisms including bacteria have great diversity and may have different sensitivity to EMF, which are known to have wide spectrum and different characteristics [1]. For many years, the electromagnetic irradiation (EMI) effects of the extremely low frequency electromagnetic fields (ELF-EMF) on biological systems have been debated. Some studies showed there was no significant biological effect [2-5], while others demonstrated significant effect of the ELF irradiation [6-10], especially the frequency of $50 \mathrm{~Hz}$, which can be found everywhere in daily life (such as power lines, ordinary household appliances, and communication devices) [11]. As for the biological effect on human health, both harmful and useful effects have been reported [12-16]. The root cause of the conflicting results is due to the lack of essential controls for experiments conducted [14].

The ELF-EMF effects are dependent on various factors such as frequency, field strength, exposure time, cultivation mode and genotype [17-19]. Most work with cellular systems was performed by choosing one specific frequency or one modulation frequency with varying field intensities. Screening of a wide range of frequency and intensity has not yet been done.

As for the mechanism of the effect, water, as the major constituent of growth medium as well as biological systems, was speculated to play a role in mediating the EMI effect on E. coli, and the mediated effect through water at extremely high frequencies of 1.8, 53, 70.6, and $73 \mathrm{GHz}$ on E. coli growth was clearly demonstrated [20,21]. However, there is no information regarding the mediating effect of water for ELF.
For this study, Escherichia coli strain DH5a was chosen to examine the electromagnetic irradiation effect of ELF. We started by examining numerous frequency combinations with antibacterial functions (i.e. E. coli inhibitory programs, chlorine, ozone, antibiotic and general antiseptic programs) listed in the Rife database (https://www.spooky2. $\operatorname{com} /$ ), which is a compilation of frequencies from Rife frequency researchers and can be accessed and downloaded online, and then focused on the frequency combinations below $100 \mathrm{~Hz}$.

To better understand the effect of the ELF, we designed an ELF exposure system to generate a weak uniform ELF-EMF. By using this system, a screening study was performed by sweeping frequency in the range of $0-10000 \mathrm{~Hz}$ initially, and then narrowed down to the range of $0-100 \mathrm{~Hz}$ and followed by focusing on the frequency of $50 \mathrm{~Hz}$. The primary goal was to gain more knowledge of frequency that showed the most significant impact on the growth of the E. coli.

By simultaneously examine the effect of different ranges of frequencies, including scanning a few distinctive frequencies or sweeping in different ranges of frequencies, it increased the robustness of the results. In addition, with the effort to shed light on the mechanism of biological effect, we also examined the mediating effect of $50 \mathrm{~Hz}$ through water and growth media on the growth of E. coli.

${ }^{*}$ Correspondence to: Xuemei Bai, Institute of Life Science and Technology, ENN Group, Langfang, 065001, China, E-mail: xuemei_bai@yahoo.com

Key words: extremely low frequency electromagnetic field (ELF-EMF), electromagnetic irradiation (EMI) effects, bacterial growth, Escherichia coli

Received: May 21, 2019; Accepted: May 28, 2019; Published: June 03, 2019 


\section{Materials and methods}

\section{Bacteria and preparation}

Escherichia coli strain DH5a (obtained from Institute of ENNOVA Life Science and Technology) was maintained on Luria-Bertani (LB) medium with $1.5 \%$ agar (Cat\#: A8190, Solarbio) at $4^{\circ} \mathrm{C}$ in the freezer.

For each experiment, it was taken from freezer and suspended in a $50 \mathrm{ml}$ Erlenmeyer flask containing $30 \mathrm{ml}$ of LB liquid medium, comprising of $5 \mathrm{~g} / \mathrm{L}$ yeast extract (Cat\#: LP0021, Oxoid), $10 \mathrm{~g} / \mathrm{L}$ Tryptone (Cat\#: LP0042, Oxoid), $10 \mathrm{~g} / \mathrm{L} \mathrm{NaCl}$ (Cat\#: S5886-1KG, Sigma), with $\mathrm{pH}$ set at 7 and agitation of $200 \mathrm{rpm}$ on a rotary shaker at $37^{\circ} \mathrm{C}$ for $12 \mathrm{~h}$. This process ensured that bacteria were activated into the stage of exponential growth, thereafter the activated cells were used as a seed of inoculation for subsequent irradiation experiments.

For the irradiation experiments, the seed was inoculated into LB medium to obtain the suspensions of bacterial cells with an optical density of OD600 $\mathrm{nm}=0.1$ (equivalent to a cell density of $1.0 \times 10^{6} \sim 10^{7}$ cell per $\mathrm{mL}$ suspension). Then the suspension was transferred into $50 \mathrm{ml}$ Erlenmeyer flasks containing $5 \mathrm{ml}$ of suspension (thickness of the suspension was about $5 \mathrm{~mm}$ ) to be used as the test samples. It should be noted that the cell density and thickness were optimized in the foregoing experiments to make sure the test sample was prepared appropriately for all experiments.

\section{Electromagnetic irradiation procedure}

Figure 1 shows the schematic diagram of the ELF exposure system. ELF exposure system including coils and culture flask has been specifically designed so it can fit inside the incubator with chambers to keep the culture flasks in place. The samples were divided into two groups, with one as the EMF-treated group, and the other the control or untreated group. In order to make sure the ELF-EMF generated was uniform for all samples, a flat coil (47 mm diameter, $7 \mathrm{~mm}$ height) was adopted to fit the bottom of the culture flask. The irradiation procedure was performed by connecting the coil to a commercially available frequency generator (FY2300 type, FeelTech Enterprise, China, http:// www.feeltech.net/).

i) For evaluation the EMI effect of Rife frequencies on E. coli, three groups and a total of 14 programs of frequencies were used for the experiment (Table 1). Group A included 7 programs which were related to the inhibitory effect of $E$. coli, and group B encompassed 4 programs regarding frequencies with anti-bacterial properties, and group $\mathrm{C}$ were programs with frequencies below $100 \mathrm{~Hz}$.

ii) For the wave-scanning effect experiment, the scanning wave was set in the ranges of $0-100 \mathrm{~Hz}, 100-500 \mathrm{~Hz}, 500-1000 \mathrm{~Hz}, 0-1000 \mathrm{~Hz}$,

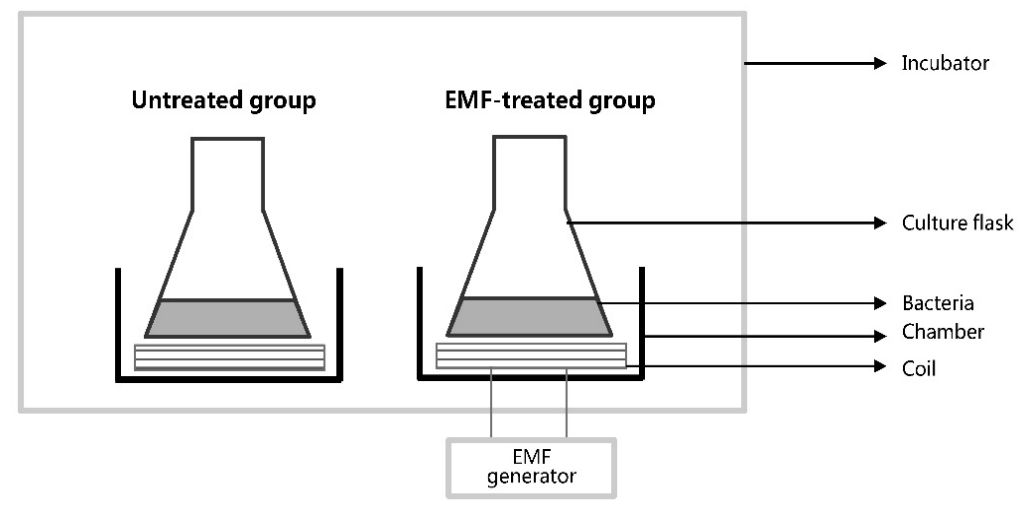

Figure 1. Schematic illustration of the experimental design used for the measurement of growth characteristics of E. coli

Table 1. List of Rife frequency used for evaluation of EMI effect on $E$ Coli

\begin{tabular}{|c|c|c|c|}
\hline Groups & Programs* & Frequencies (Hz) & Description \\
\hline \multirow[t]{7}{*}{$\mathbf{A}$} & E Coli 1 (CAFL) & $332.5,798,1729,7847$ & $\begin{array}{l}\text { Clearly related to the inhibitory effect of Escherichia } \\
\text { coli }\end{array}$ \\
\hline & E Coli 1 (XTRA) & $971.66,974.14,12250,12281.25$ & \\
\hline & E Coli 3 (XTRA) & $882.44,11125$ & \\
\hline & E Coli 5 (XTRA) & $\begin{array}{c}330,358,539,556,634,642,776,800,840,856 \\
934,1000,1244,1712,1730,7847\end{array}$ & \\
\hline & E Coli 6 (XTRA) & $882.44,974.14,17724.2,19566.31$ & \\
\hline & E Coli $(\mathrm{HC})$ & 356000 & \\
\hline & E Coli (BIO) & $282,333,413,957,1320,172$ & \\
\hline \multirow[t]{4}{*}{ B } & $\begin{array}{l}\text { Wide Spectrum } \\
\text { Antibiotic } 4 \text { (XTRA) }\end{array}$ & $727,787,802,880,465$ & Related to the general inhibition of bacteria \\
\hline & Chlorine 35cl (XTRA) & $208.56,224.84,19136.72$ & \\
\hline & Chlorine 37cl (XTRA) & $173.62,187.15,15929.69$ & \\
\hline & Ozone Generate (XTRA) & $78,16,15.99$ & \\
\hline \multirow[t]{3}{*}{$\mathbf{C}$} & $\begin{array}{l}\text { Accelerate Injury } \\
\text { Healing (XTRA) }\end{array}$ & 47 & $\begin{array}{l}\text { Not related to the biological effects of bacteria, but } \\
\text { with similar to frequencies of "Ozone Generate" }\end{array}$ \\
\hline & $\begin{array}{l}\text { Adynamia Geriatric } \\
\text { (XTRA) }\end{array}$ & $60,27.5$ & \\
\hline & $\begin{array}{l}\text { Frequency Fatigue } \\
\text { (CAFL) }\end{array}$ & $10.55,7.83$ & \\
\hline
\end{tabular}


and $0-10000 \mathrm{~Hz}$ respectively; for frequency lower than $100 \mathrm{~Hz}$, the scanning wave was set in the ranges of $0-20 \mathrm{~Hz}, 20-40 \mathrm{~Hz}, 40-60 \mathrm{~Hz}$, $60-80 \mathrm{~Hz}$, and $80-100 \mathrm{~Hz}$ respectively. The duration of irradiation was set for $1 \mathrm{~h}$.

iii) For the single-wave effect experiment, a $50 \mathrm{~Hz}$ was chosen to examine the EMI effect with respect to the exposure time. The irradiation time was set for $1 \mathrm{~h}, 2 \mathrm{~h}, 4 \mathrm{~h}, 8 \mathrm{~h}$ and $16 \mathrm{~h}$, and all the other variables were kept the same as the wave-scanning effect experiment.

iv) For investigating the mediated effect of the frequency at $50 \mathrm{~Hz}$ on bacteria, three sets of samples were set up, which included 1) growth medium with bacterial culture (MB), 2) growth medium only $(\mathrm{M})$, and 3) double distilled water only (W). For the EMF-treated groups, the three samples were exposed to the $50 \mathrm{~Hz}$ irradiation at room temperature for $1 \mathrm{~h}$ without agitation. After irradiation, fresh medium was added into $\mathrm{MB}$, bacteria (same batch as used for $\mathrm{MB}$ ) into $\mathrm{M}$, and bacteria (same batch as used for $\mathrm{MB}$ ) and the growth medium into $\mathrm{W}$, followed by adjusting all the samples to the appropriate cell density as stated above. Upon finishing, all samples were immediately placed into the incubator at $37^{\circ} \mathrm{C}$ with agitation of $120 \mathrm{rpm}$ for $1 \mathrm{~h}$.

For the Rife frequency's evaluation experiment, a $10 \mathrm{~V}$ wave scanning with different programs of Rife frequencies (intensity range: 0.1-3.0 $\mathrm{mT}$ ) was used. For the wave-scanning effect experiment, a $10 \mathrm{~V}$ sine wave scanning was generated in the frequency range of $0-10000 \mathrm{~Hz}$ (0.1-3.0 $\mathrm{mT}$ ) with the repetition rate of 60 seconds, and for the singlewave effect experiment, a continuous $20 \mathrm{~V}$ sine wave at the frequency of $50 \mathrm{~Hz}(2.3-2.5 \mathrm{mT})$ was generated.

To investigate the growth characteristics of E. coli exposed to the ELF-EMF, the temperature was set at $37^{\circ} \mathrm{C}$ in an incubator with the temperature variation less than $0.3^{\circ} \mathrm{C}$ (non-thermal effects). The samples were kept in suspension by placing on a shaker at $120 \mathrm{rpm}$ during the experiment.

For all experiments, the control, also referred to as the untreated sample, was set up in triplicates under the same culturing conditions (e.g. placed on the same type of coil in the same incubator) as that for the treated group. The only difference is that the control group received no irradiation by keeping the frequency generator powered off.

\section{Bacterial growth determination}

The growth of cells was indicated by monitoring optical density at the wavelength of $750 \mathrm{~nm}$ using a UV-VIS Auto spectrophotometer (UV-2800 type, UNIC, China). Growth rate of culture was calculated as the optical density change over time $\left(\mathrm{R}=\left(\mathrm{OD}_{\mathrm{T}}-\mathrm{OD}_{0}\right) / \mathrm{T}\right)$ by taking $\mathrm{OD}$ of samples at the time of inoculation ( 0 ) and at the end of the exposure (T). EMF exposure effect was assessed in terms of the variation of growth rate between the treated and the untreated group. The degree of variation was calculated as follows: $V(\%)=\left(R_{t}-R_{u}\right) / R_{u}$, where $R_{t}$ and $R_{u}$ were the growth rates of the treated and the untreated groups. Since the only difference between the treated and untreated groups was the irradiation, therefore, the variation of growth rate between these two groups is used to indicate the effect of the irradiation. All experiments were performed in triplicates with the data averaged and their standard deviation calculated.

\section{Results}

\section{EMI effect of rife frequencies on bacterial growth}

Three groups of programs were tested. The results showed that growth rate was not affected substantially under the irradiation of the frequency programs from group A (Figure 2A). Three sets of frequencies tested enhanced the growth slightly, while the other 4 sets suppressed the growth, with effect less than 7\%; For the effect of programs of group $B$, there was a significant enhancement induced by the frequencies of "Ozone Generate", and the increase in growth reached 25\%, while the effect with other programs were less than $10 \%$. The Ozone Generate program contains three frequencies under $100 \mathrm{~Hz}(78 \mathrm{~Hz}, 16 \mathrm{~Hz}, 15.99$ $\mathrm{Hz}$ ), so we further examined programs in group $\mathrm{C}$ with frequencies below $100 \mathrm{~Hz}$ but not related to antibacterial functions. The results showed a significant enhancement in growth by all programs of group C (Figure 2B).

\section{EMI effect on bacterial growth for frequencies at different ranges}

The growth rate was not affected when scanning in a relatively large range of frequency such as $0-10,000 \mathrm{~Hz}$ and $0-1,000 \mathrm{~Hz}$. However, the growth rate was slightly enhanced at the lower range of frequencies when scanning at a relatively smaller range such as $500-1,000 \mathrm{~Hz}$, and

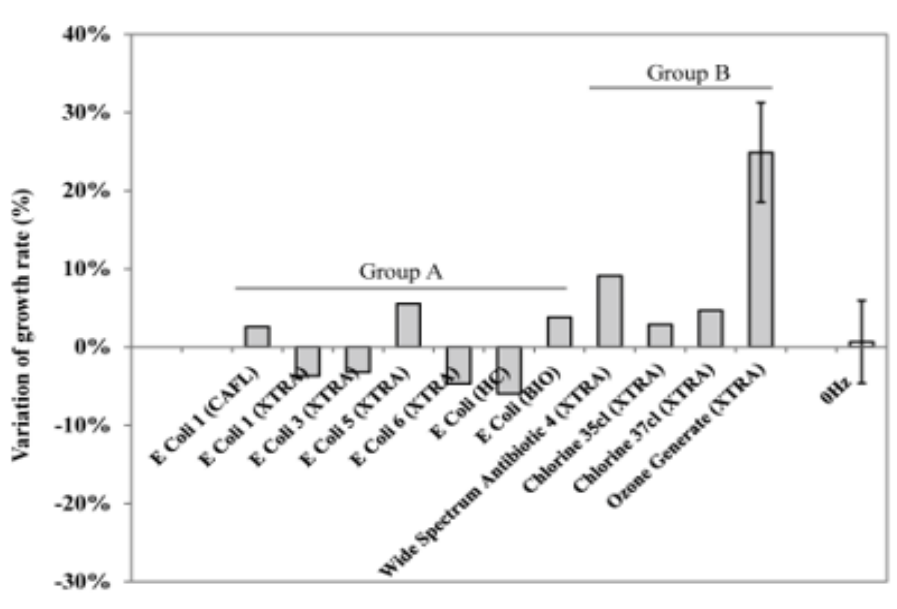

(A)

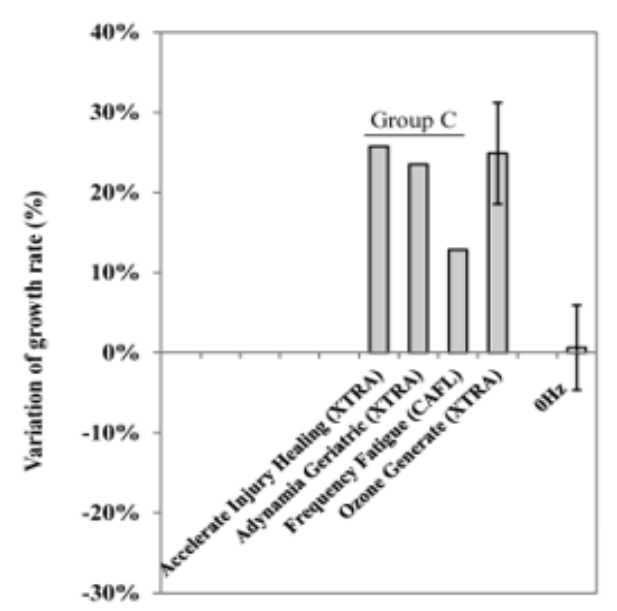

(B)

Figure 2. The growth rate variation of $E$. coli after irradiation by EMF at different Rife frequencies programs: (A) programs from group A related to the inhibitory effect of $E$. coli and group B with anti-bacterial properties (B) Programs from group C with frequencies below $100 \mathrm{~Hz}$, with no anti-bacterial properties stated in the database. Error bars representing standard deviation of triplicate samples 
$100-500 \mathrm{~Hz}$; by lowering the frequency to $0-100 \mathrm{~Hz}$, the growth rate was significantly enhanced with an average greater than $10 \%$ (Figure $3 \mathrm{~A})$. By narrowing down the range of the frequency to $0-100 \mathrm{~Hz}$, the EMI effect on E. coli growth was much more pronounced with the maximum increase reaching over $20 \%$ (Figure $3 \mathrm{~B}$ ). The effect was frequency dependent, and the range of $40-60 \mathrm{~Hz}$ and $60-80 \mathrm{~Hz}$ were the most effective in promoting growth of the $E$. coli. Based on these results, $50 \mathrm{~Hz}$ was selected for subsequent single-wave experiments.

\section{EMI effects on bacterial growth with respect to exposure time}

The EMI effect for frequency at $50 \mathrm{~Hz}$ was dependent on exposure time as shown in Figure 4, where a significant increase in growth rate (>25\%) was observed for groups with exposure time of $1 \mathrm{~h}$ and $2 \mathrm{~h}$, while no promotion in growth observed for groups with exposure time of $4 \mathrm{~h}, 8 \mathrm{~h}$, and $16 \mathrm{~h}$. On the other hand, the prolonged exposure time $(8 \mathrm{~h}$ and $16 \mathrm{~h})$ resulted in a slight decrease in growth rates $(6 \%)$ for the treated group relative to the untreated group.

\section{EMI effect on bacteria and indirect effect through medium and water}

Consistent with the results obtained above, as shown in Figure 5, there was a significant increase in growth rate for the group with both

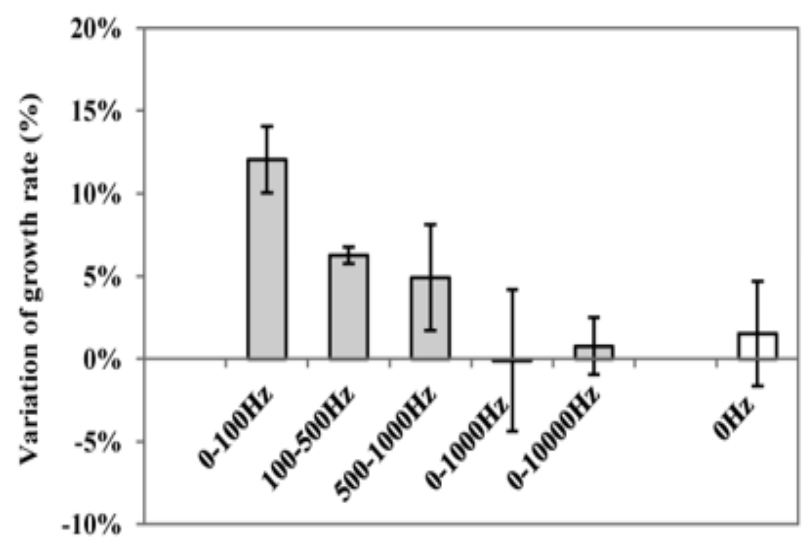

(A) the growth medium and bacteria being exposed to the $50 \mathrm{~Hz}$ irradiation for $1 \mathrm{~h}$. However, for the other groups, no difference in growth rates was observed between the treated and untreated groups when the growth medium or the water was exposed to the $50 \mathrm{~Hz}$ irradiation only.

\section{Discussion}

Some of the frequency combinations supposed to produce an inhibition effect in the Rife database exhibited a promoting effect on the growth of E. coli, especially the "Ozone Generate" program containing three frequencies below $100 \mathrm{~Hz}$. So, we further selected other programs with frequencies below $100 \mathrm{~Hz}$ but with no anti-bacterial functions stated in the database and found the same enhancing effect on the growth of E. coli. This is very intriguing results which led us to systematically examine the effect of frequencies under $100 \mathrm{~Hz}$ on the growth of E. coli.

The issue of health hazards associated with EMFs produced by power lines or household appliances has been continuously debated, including different effects and the mechanism of these effects. Some even argued that such an effect may or may not exist due to the lack of essential controls of many researches published in this area [14]. To avoid such a concern, we used frequency at $0 \mathrm{~Hz}$ as control and

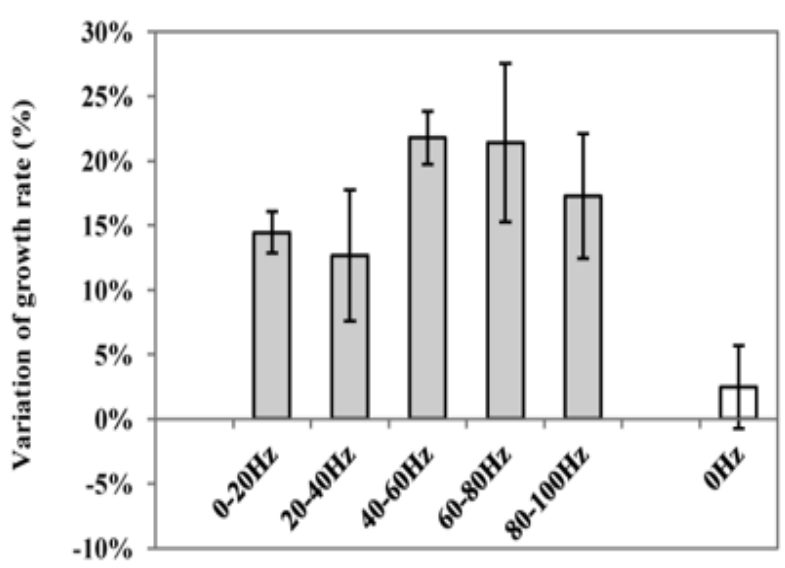

(B)

Figure 3. The growth rate variation of $E$. coli after irradiation by EMF at different frequency ranges: (A) the scanning wave in the range of 0-10000 Hz, and (B) the scanning wave in the range of $0-100 \mathrm{~Hz}$. Control: EMF-treated with $0 \mathrm{~Hz}$ radiation; Error bars representing standard deviation of triplicate samples

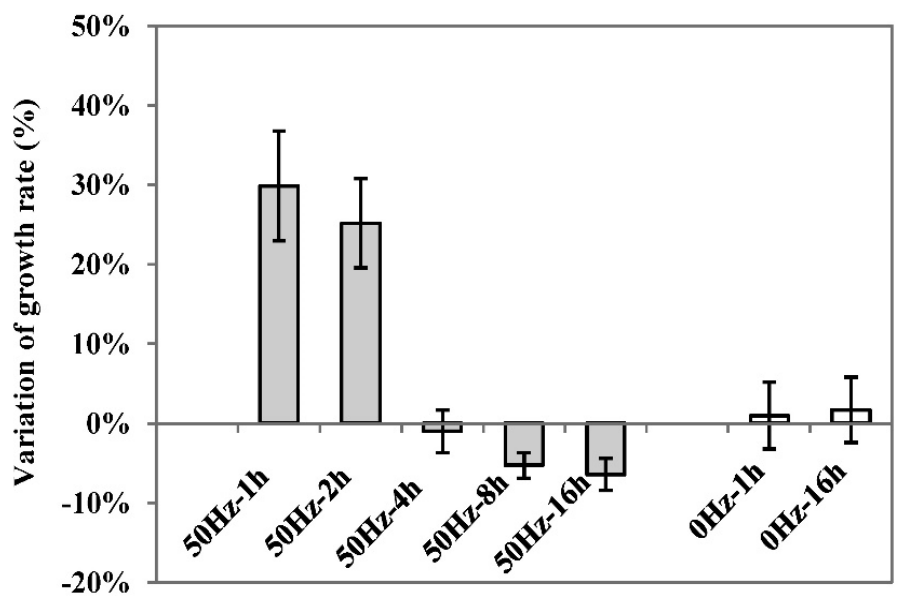

Figure 4. The EMF effect of frequency at $50 \mathrm{~Hz}$ on the growth rate of E. coli at different exposure time: $1 \mathrm{~h}, 2 \mathrm{~h}, 4 \mathrm{~h}, 8 \mathrm{~h}$ and $16 \mathrm{~h}$; Control: EMF-treated with $0 \mathrm{~Hz}$ radiation for $1 \mathrm{~h}$ and 16 $\mathrm{h}$ respectively. Error bars representing standard deviation of triplicate samples 


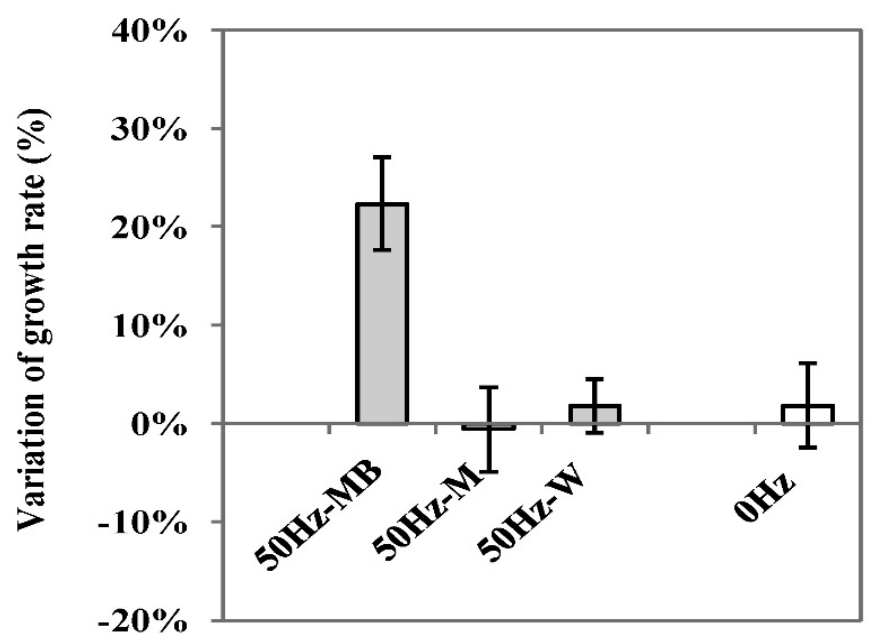

Figure 5. The EMF effect of frequency at $50 \mathrm{~Hz}$ on E. coli growth rate through irradiation of medium with bacteria (MB), medium only (M), and water only (W). Error bars representing standard deviation of triplicate samples

examined multiple ranges of frequencies simultaneously, which can all be compared to the targeting frequency. The results obtained here provided direct evidence of biological effects exerted by ELF-EMI at $0-100 \mathrm{~Hz}$, especially $50 \mathrm{~Hz}$.

It was reported that the cell cycle of human peripheral lymphocytes in culture was accelerated when exposed to $50 \mathrm{~Hz}$ irradiation of $5 \mathrm{mT}$ [22], while an increased cell proliferation is regarded as cell transformation [23]. A growth increase of anchorage independent JB6 cells after exposure to a $60 \mathrm{~Hz}(1.1 \mathrm{mT})$ was demonstrated [24]. The EMI effect of $50 \mathrm{~Hz}$ on bacteria is of special interest because EMFs $(50 / 60 \mathrm{~Hz})$ can be caused by an alternating current (AC) which is inevitable for modern society.

In addition, EMI effect of $50 \mathrm{~Hz}$ showed the exposure time dependence, where a significant increase of the growth after exposure 1 $\mathrm{h}$ but a slight decrease after exposure $4 \mathrm{~h}$ was observed. More in-depth study is needed to address the reasons of the time-dependent effect. It could be cell damage due to EMI exposure over time or it could be caused by worse and worse growth conditions in the treatment group due to the fast growth in the first couple of hours. Therefore, to evaluate the EMI effect, the cell density, cell viability, parameters of the growth media, should be all taken into consideration.

Many investigations suggested that EMI is absorbed by water and the effects on bacteria can be mediated by the changes in water clusters structures [25-27], and these effects might be long-term $[26,28,29]$. However, unlike the EHF-EMF, water or media treated with ELF-EMF did not induce an EMI effect for bacteria cultured with it, indicating no mediated effect (indirect effect) of ELF-EMF for this study. For future work, the experiment should be performed in higher electromagnetic field levels to investigate whether stronger ELF-EMF is effective for a mediating effect through medium or water.

\section{Conclusion}

This study reported the significant biological effect of extremely low-frequency electromagnetic irradiation on growth of $E$. coli. The results demonstrated that the growth rate was noticeably affected when treated by the EMI of frequencies below $100 \mathrm{~Hz}$, whether they are combination of frequencies below $100 \mathrm{~Hz}$ or scanning frequencies in the range of $0-100 \mathrm{~Hz}$. It was found that the frequency in the range of 40-60
$\mathrm{Hz}$ had the most significant effect on growth rate. The EMI effect of 50 $\mathrm{Hz}$ on the growth of bacteria was time-dependent, with an increase in growth within $2 \mathrm{~h}$ of irradiation, and an inhibition when the exposure time was over $4 \mathrm{~h}$. It was demonstrated that the $50 \mathrm{~Hz}$ irradiation was a direct effect on the bacteria cells as treating media or water alone did not yield an EMI effect for bacteria cultured with it. These findings have applicable values for the fine chemical fermentation processes as biomass of $E$. coli could be enhanced significantly through the appropriate EMI stimulation. On the other hand, it also raises concerns regarding safety of these frequencies on the biological systems, which needs to be examined more systematically.

\section{Acknowledgments}

The authors would like to thank the ENN Group for the funding.

\section{References}

1. Soghomonyan D, Trchounian K, Trchounian A (2016) Millimeter waves or extremely high frequency electromagnetic fields in the environment: what are their effects on bacteria?. Appl Microbiol Biotechnol 100: 4761-4771.

2. De Haas WG, Lazarovici MA, Morrison DM (1979) The effect of low frequency magnetic fields on the healing of the osteotomized rabbit radius. Clin Orthop Relat Res 145: 245-251. [Crossref]

3. Devereaux MD, Hazleman BL, Thomas PP (1985) Chronic lateral humeral epicondylitis--a double-blind controlled assessment of pulsed electromagnetic field therapy. Clin Exp Rheumatol 3: 333-336. [Crossref]

4. Harrison MHM, Bassett CAL (1997) The results of a double-blind trial of pulsed electromagnetic frequency in the treatment of Perthes' disease. J Pediatric Orthopaedics 17: 264-265.

5. Karasek M, Czernicki J, Woldanska-Okonska M (2000) Chronic exposure to 25-80- $\mu \mathrm{T}$, $200-\mathrm{Hz}$ magnetic field does not influence serum melatonin concentrations in patients with low back pain. J Pineal Res 29: 81-85.

6. Akbarnejad Z, Eskandary H, Vergallo C, Nematollahi-Mahani SN, Dini L, et al. (2017) Effects of extremely low-frequency pulsed electromagnetic fields (ELF-PEMFs) on glioblastoma cells (U87). Electromagn Biol Med 36: 238-247. [Crossref]

7. Amaroli A, Trielli F, Bianco B, Giordano S, Moggia E, et al. (2006) Effects of a $50 \mathrm{~Hz}$ magnetic field on Dictyostelium discoideum (Protista). Bioelectromagnetics 27: 528 534 .

8. Gu S, Lu G, Wu Y, Li S, Zhao Y, et al. (2012) A Study of the Interaction between ELFEMF and Bacteria. Advances Electric Electronics pp: 243-254.

9. Mittenzwey R, Sussmuth R, Mei W (1996) Effects of extremely low-frequency electromagnetic fields on bacteria-The question of a co-stressing factor. Bioelectrochem Bioenerg 40: 21-27. 
10. Rodriguez Justo O, Perez VH, Chacon Alvarez D, Monte Alegre R (2006) Growth of Escherichia coli under extremely low-frequency electromagnetic fields. Appl Biochem Biotechnol 134: 155-163.

11. Simko M, Mattsson MO (2004) Extremely low frequency electromagnetic fields as effectors of cellular responses in vitro: possible immune cell activation. J Cell Biochem 93: 83-92.

12. Feychting M, Forssén U, Floderus B (1997) Occupational and Residential Magnetic Field Exposure and Leukemia and Central Nervous System Tumors. Epidemiology 8: 384-389.

13. Li CY, Thériault G, Lin RS (1997) Residential exposure to 60-Hertz magnetic fields and adult cancers in Taiwan. Epidemiology 8: 25-30.

14. Saffer JD, Thurston SJ (1995) Cancer risk and electromagnetic fields. Nature 375: 22 23. [Crossref]

15. Savitz DA, Wachtel H, Barnes FA, John EM, Tvrdik JG, et al. (1988) Case-control study of childhood cancer and exposure to $60-\mathrm{Hz}$ magnetic fields. Am J Epidemiol 128: 21-38.

16. Wertheimer N, Leeper ED (1979) Electrical wiring configurations and childhood cancer. Am J Epidemiol 109: 273-284. [Crossref]

17. Fojt L, Strasak L, Vetterl V, Smarda J (2004) Comparison of the low-frequency magnetic field effects on bacteria Escherichia coli, Leclercia adecarboxylata and Staphylococcus aureus. Bioelectrochemistry 63: 337-341.

18. Strasak L, Vetterl V, Smarda J (1998) The effect of low-frequency electromagnetic fields on living organisms. Sb Lek 99: 455-464.

19. Strasak L, Vetterl V, Smarda J (2002) Effects of low-frequency magnetic fields on bacteria Escherichia coli. Bioelectrochemistry 55: 161-164.
20. Torgomyan H, Hovnanyan K, Trchounian A (2013) Escherichia coli growth changes by the mediated effects after low-intensity electromagnetic irradiation of extremely high frequencies. Cell Biochem Biophys 65: 445-454.

21. Torgomyan H, Kalantaryan V, Trchounian, A (2011) Low intensity electromagnetic irradiation with 70.6 and $73 \mathrm{GHz}$ frequencies affects Escherichia coli growth and changes water properties. Cell Biochem Biophys 60: 275-281.

22. Antonopoulos A, Yang BC, Stamm A, Heller WD, Obe G, et al. (1995) Cytological effects of $50 \mathrm{~Hz}$ electromagnetic-fields on human-lymphocytes in-vitro. Mutation Research Letters 346: 151-157.

23. Katsir G, Parola AH (1998) Enhanced proliferation caused by a low frequency weak magnetic field in chick embryo fibroblasts is suppressed by radical scavengers. Biochem Biophys Res Commun 252: 753-756.

24. West RW, Hinson WG, Lyle DB (1994) Enhancement of anchorage-independent growth in jb6 cells exposed to 60 hertz magnetic-fields. Bioelectrochem Bioenerg 34: 39-43.

25. Binhi VN, Rubin AB (2007) Magnetobiology: The kT Paradox and Possible Solutions Electromagn Biol Med 26: 45-62.

26. Fesenko EE, Geletyuk VI, Kazachenko VN, Chemeris NK (1995) Preliminary microwave irradiation of water solutions changes their channel-modifying activity. FEBS Lett 366: 49-52.

27. Suresh SJ, Satish AV, Choudhary A (2006) Influence of electric field on the hydrogen bond network of water. $J$ Chem Phys 124: 74506.

28. Belovolova LV, Glushkov MV, Vinogradov EA, Babintsev VA, Golovanov VI, et al. (2009) Ultraviolet fluorescence of water and highly diluted aqueous media. Physics Wave Phenomena 17: 21-31.

29. Sunkari VG, Aranovitch B, Portwood N, Nikoshkov A (2011) Effects of a low-intensity electromagnetic field on fibroblast migration and proliferation. Electromagn Biol Med 30: $80-85$.

Copyright: $(\mathbb{C} 2019$ Chen Y. This is an open-access article distributed under the terms of the Creative Commons Attribution License, which permits unrestricted use, distribution, and reproduction in any medium, provided the original author and source are credited. 